\title{
The mating system in sympatric populations of Carduus nutans, $C$. acanthoides and their hybrid swarms
}

\author{
Suzanne I. Warwick* and \\ Brian K. Thompson $\dagger$
}

\author{
* Biosystematics Research Centre and \\ $\dagger$ Engineering and Statistical Research Centre, \\ Agriculture Canada, Research Branch, \\ Central Experimental Farm, Ottawa, Ontario, \\ Canada, K1A OC6.
}

Levels of outcrossing were compared in two sympatric weedy species of Carduus, $C$. nutans and $C$. acanthoides and their hybrid swarms from Grey County, Ontario, Canada in order to determine whether: (i) a departure from random outcrossing could be demonstrated in the Grey County populations; (ii) there were species differences in outcrossing rates and selfing potential; (iii) differences were evident between pure populations of the parental taxa and the hybrid swarms; and (iv) there was evidence for spatial substructuring of the populations or inter-plant variation in outcrossing rates. Self-fertilization studies, conducted in the greenhouse on individuals of both species, indicated varying degrees of self-fertility, up to 60 per cent among plants of each species. Two estimates of outcrossing, $t$ and $t_{H}$, were obtained from analyses of three polymorphic enzyme loci, for three populations of each species and three hybrid swarms. Outcrossing rates, $t_{\mathrm{H}}$, were based on Wright's inbreeding coefficient, $F$, calculated from the observed levels of heterozygosity pooled over all progeny per population, whereas outcrossing rates, $t$, were obtained from analyses of progeny genotype arrays using maximum likelihood estimation procedures. Both multilocus estimates of the outcrossing rate $t$ and $t_{\mathrm{H}}$ averaged over all loci, were significantly less than $1 \cdot 0$ for all nine populations studied, indicating significant departures from random outcrossing. No consistent differences in outcrossing rates were detected for populations of the two parental species and the three hybrid swarms. However, considerable inter-plant variation in values of $t$ were observed in both Carduus species, although the data did not provide evidence for population substructuring.

\section{INTRODUCTION}

Knowledge of the breeding system is important in understanding the genetic composition and evolutionary potential of plant populations (Richards, 1986; Brown and Burdon, 1988). In particular, the mating system will determine genetic structure, i.e., how genetic variation is distributed within and among populations (Brown and Allard, 1970; Clegg, 1980; Hamrick 1982). Studies of plant breeding systems using polymorphic enzyme loci have demonstrated that levels of outcrossing vary considerably among species and among populations of a self-compatible species (Clegg, 1980; Hamrick, 1982; Schemske and Lande, 1985). Like other attributes of the genetic system, the rate of outcrossing is primarily under genetic control, but it is also plastic and responsive to selection and other environmental influences. For example, the mating structure of

ESRC Contribution No. C-052. plants that utilize insect pollinators will be affected by pollinator and floral availability, the latter determined by both plant density and the number and arrangement of flowers on plants being serviced by a given pollinator (Clegg, 1980; Richards, 1986). There are other factors in addition to selffertilization that can contribute to a departure from random mating in plant populations, including spatial substructuring of populations and assortative mating or variation in outcrossing among maternal genotypes (Clegg, 1980; Ritland, 1983). Flexibility in the mating system may be an essential factor in determining colonizing success of a plant species (Brown and Burdon, 1988).

The purpose of this study was to compare levels of outcrossing in two sympatric weedy species of Carduus, $C$. nutans L. $(2 n=16)$ and $C$. acanthoides L. $(2 n=22)$ and their hybrid swarms from Grey County, Ontario, Canada. The two Carduus species show distinct differences in flower head size, number and arrangement, with the solitary, nodding flower heads of $C$. nutans being much 
larger than those of $C$. acanthoides, which is characterized by clusters of erect flower heads. Such differences presumably affect resource availability and patterns of pollinator activity and may well be reflected in differential rates of actual outcrossing. Both species are introduced weeds, primarily of roadsides, disturbed ground, fields and pasturelands in Canada (Desrochers et al., $1988 a)$. Both are self-compatible and are visited primarily by Bombus and Apis spp., suggesting a high degree of outcrossing. Indeed, evidence for random outcrossing was obtained for two Kansas populations of $C$. nutans, while those from semiisolated plants in the same area were highly variable (Smyth and Hamrick, 1984). Estimates of outcrossing rates are not available for $C$. acanthoides.

The Grey County hybrid zone offered a number of distinct advantages for this study. The two parental taxa occur sympatrically, ensuring that potential pollinator availability is similar for both. Carduus populations from this region have been intensively studied over a number of years, so that an extensive data base has been established (Moore and Mulligan, 1956, 1964; Warwick and Bain, 1987; Warwick et al., 1989). Studies by Moore and Mulligan (1964) have provided evidence for variable and quite high rates of selffertility among plants of both species from this region, suggesting the potential for departures from random mating. Since the region is a hybrid zone, characterized by both pure populations of each of the two parental species and numerous hybrid swarms, one is able to test whether hybridization and backcrossing, with their potential interruption of the plant's genetic system (Moore and Mulligan, 1964), have affected rates of outcrossing in the hybrid swarms relative to parental populations. Previous studies by (Warwick et al., 1989) have shown that although pollen fertility was high for all plants from the three hybrid swarms included in this study, differential seed set among plants was evident.

In the present study, levels of outcrossing were estimated for three populations of each of $C$. nutans and $C$. acanthoides and three hybrid swarms in order to determine whether: (i) a departure from random outcrossing could be demonstrated in the Grey County populations; (ii) there were species differences in outcrossing rates and selfing potential; (iii) differences were evident between pure populations of the parental taxa and the hybrid swarms; and (iv) there was evidence for spatial substructuring of the populations or inter-plant variation in outcrossing rates.

\section{MATERIALS AND METHODS}

\section{Materials}

Table 1 gives the location, habitat and relative density of the nine populations studied, including three populations of $C$. nutans, three populations of $C$. acanthoides and three hybrid swarms. Voucher specimens from each of the nine populations have been placed in the Herbarium at Agriculture Canada, Ottawa, Ontario.

\section{Self-fertilization}

Seed set under self-pollination was measured by bagging five flower heads from 22 and 17 individuals of $C$. acanthoides and $C$. nutans, respectively. These had been grown in the greenhouse from seed collected from each of the three populations of each species.

Table 1 Location, habitat, and population density of the nine populations studied; all were located in Grey County, Ontario, Canada

\begin{tabular}{|c|c|c|}
\hline \multicolumn{2}{|c|}{ Species and population } & \multirow{4}{*}{$\begin{array}{l}\text { Location, habitat, population density } \\
\text { Lot 10, Conc. 2, Derby Township, Grey County. Pasture, plants widely spaced } \\
\text { Lot 12, Conc. 20, Keppel Township, Grey County. Disturbed wasteground, plants dense to widely spaced } \\
\text { Lot 26, Conc. 2, Sarawak Township, Grey County. Abandoned gravel pit, wasteground, dense stand }\end{array}$} \\
\hline C. acanthoides & A1 & \\
\hline & $\mathrm{A} 2$ & \\
\hline & A3 & \\
\hline \multirow[t]{3}{*}{ C. nutans } & N1 & $\begin{array}{l}\text { Lot } 24 \text {, Conc. } 2 E \text {, Glenelg Township, Grey County. Gravel field, wasteground, plants dense to widely } \\
\text { spaced }\end{array}$ \\
\hline & $\mathrm{N} 2$ & Lot 55 , Conc. $2 \mathrm{~W}$, Bentinck Township, Grey County. Pasture, cattle, plants dense to widely spaced \\
\hline & N3 & Lot 15, Conc. 1E, Glenelg Township, Grey County. In and along edge of wheatfield, plants widely spaced \\
\hline \multirow[t]{3}{*}{ Hybrid swarms } & H1 & $\begin{array}{l}\text { Lot } 15 \text {, Conc. 1N, Artemesia Township, Grey County. Pasture, sheep, plants dense to widely spaced } \\
\text { elsewhere }\end{array}$ \\
\hline & $\mathrm{H} 2$ & Lot 117 , Conc. 1E, Artemesia Township, Grey County. Gravel pit, disturbed wasteground, dense stands \\
\hline & H3 & ot 28 , Conc. $1 \mathrm{~W}$, Bentinck Township, Grey County. Pasture, cattle, plants widely spaced \\
\hline
\end{tabular}




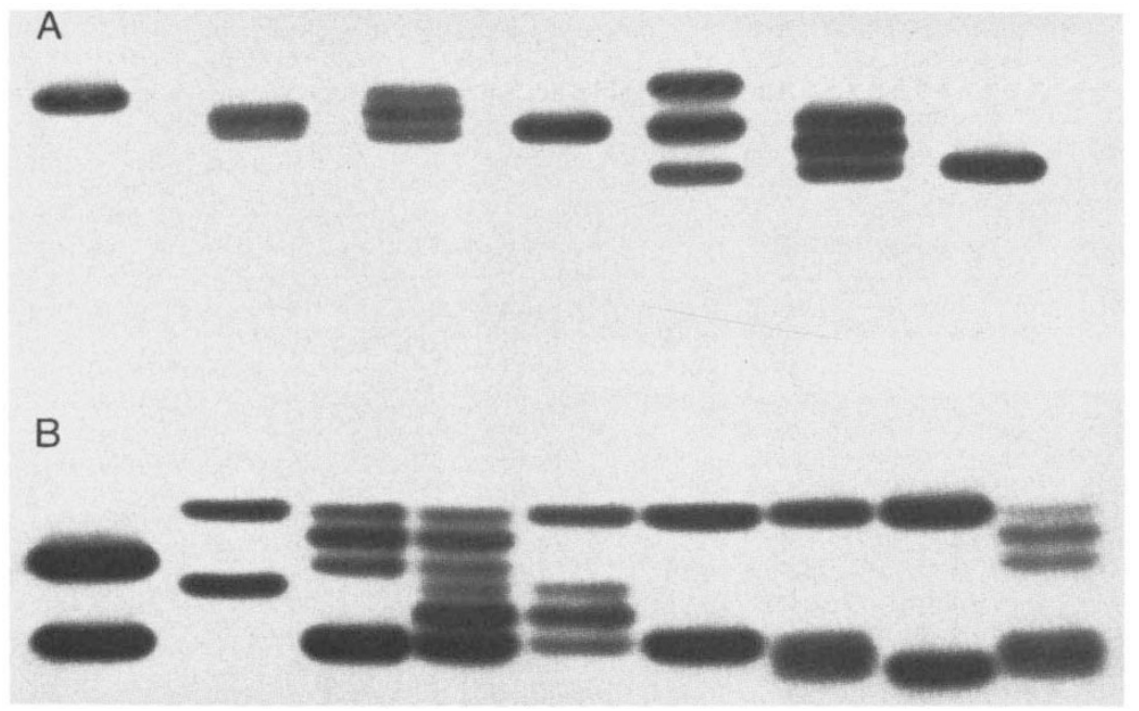

Figure 1 (a) Phosphoglucose isomerase variation patterns at locus 2 . Homozygotes for alleles $0.49,0.43$ and 0.36 are shown in lanes 1,4 , and 7 , respectively; heterozygotes for alleles $0.46 / 0 \cdot 43,0 \cdot 49 / 0 \cdot 43,0.49 / 0 \cdot 36$, and $0.43 / 0.36$ are shown in lanes 2,3 , 5 , and 6, respectively; A homozygote for the allele 0.46 is not illustrated. (b) Triose phosphate isomerase variation patterns at locus 1 with alleles 0.70 and 0.61 and locus 2 with alleles $0.58,0.49$, and 0.41 . At locus 1 , homozygotes for allele 0.70 are shown in lanes $2,5-8$, and for allele 0.61 in lane 1 and the heterozygote $0.70 / 0.61$ in lanes 3 , 4, and 9 . At locus 2 , homozygotes for allele 0.58 is shown in lane 2 , for allele 0.49 in lanes 1,3 , and 6 and for allele 0.41 in lane 8 ; heterozygotes for $0.58 / 0.49$ in lanes 4 and 5 and for $0.49 / 0.41$ in lanes 7 and 9.

\section{Outcrossing rates}

Estimates of outcrossing in the nine field populations were calculated using allozyme data at three polymorphic enzyme loci. These include phosphoglucose isomerase ( $P g i-2$, four alleles, fig. $1(\mathrm{~A}))$ and triose phosphate isomerase ( Tpi-1, two alleles and Tpi-2, three alleles, fig. 1(B)). The electrophoretic methods have been given in Desrochers et al. (1988b). Inheritance studies were carried out to verify simple Mendelian segregation of the alleles at each locus; the results are given in table 2. From 5 to 12 (usually 10 ) progeny were surveyed in each of 32 to 44 families (seedlings grown from seeds collected from single mother plants in the field) for a total of 336 to 434 seedlings per population (table 3 ).

Proportional representation of a population's genotypes and equal pollen production was assumed in the analyses (Clegg, 1980). Allele frequencies in the progeny and ovule and pollen gene pools were estimated for the most common alleles at each of the three allozyme loci for each of the populations (table 3 ). Standard errors for progeny allele frequencies were obtained using statistical package S199 (Engineering and Statistical Research Centre, Agriculture Canada). Mean ovule and pollen pool allele frequencies and their

Table 2 Genetic bases for enzyme patterns. Segregation ratios for selfed heterozygotes and results of Chi-square analyses to test for Mendelian segregation of alleles a and b in a $1: 2: 1$ ratio. ns: not significant at $P<0.05$

\begin{tabular}{|c|c|c|c|c|c|c|}
\hline \multirow[b]{2}{*}{ Genotype $^{\mathrm{a} / \mathrm{b}}$} & \multicolumn{3}{|c|}{ No. of progeny } & \multirow[b]{2}{*}{ Total } & \multirow{2}{*}{$\begin{array}{l}\text { Chi-square } \\
\text { value }\end{array}$} & \multirow{2}{*}{$\begin{array}{l}\text { Significance } \\
\text { level }\end{array}$} \\
\hline & $\mathrm{a} / \mathrm{a}$ & $a / b$ & $b / b$ & & & \\
\hline$P g i-2^{0.49 / 0.43}$ & 64 & 139 & 67 & 270 & 0.44 & ns \\
\hline Pgi- $2^{0 \cdot 46 / 0 \cdot 43}$ & 29 & 45 & 26 & 100 & $1 \cdot 18$ & ns \\
\hline $\operatorname{Pgi}-2^{0.43 / 0 \cdot 36}$ & 14 & 36 & 14 & 64 & 1.00 & ns \\
\hline Tpi-1 ${ }^{0 \cdot 70 / 0 \cdot 61}$ & 25 & 48 & 27 & 100 & 0.24 & ns \\
\hline$T p i-2^{0.58 / 0.49}$ & 20 & 52 & 18 & 90 & $3 \cdot 04$ & ns \\
\hline$T p i-2^{0 \cdot 49 / 0 \cdot 41}$ & 32 & 51 & 17 & 100 & $4 \cdot 54$ & ns \\
\hline
\end{tabular}


Table 3 Progeny allele frequencies, and inferred ovule and pollen pool allele frequencies for $P g i-2^{0.43}, T p i-1^{0 \cdot 70}$ and $T p i-2^{0.49}$ in the three populations of Carduus acanthoides (A1, A2, A3), C. nutans $(\mathrm{N} 1, \mathrm{~N} 2, \mathrm{~N} 3)$ and three hybrid swarms (H1, H2, H3) Standard errors are shown in parentheses. Number of families and total number of progeny surveyed is shown for each population

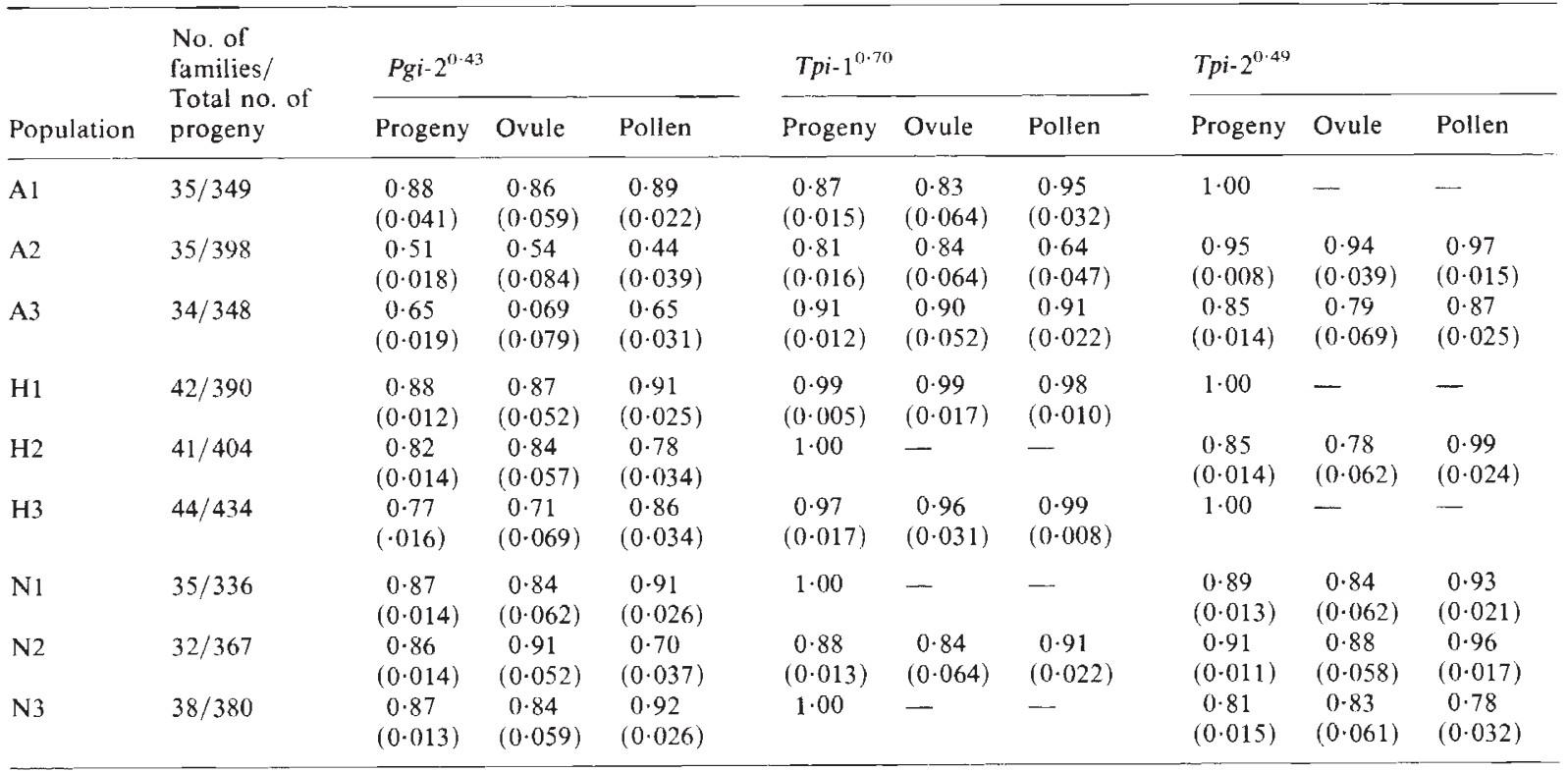

standard errors were obtained from multilocus estimation programs described by Ritland and Jain (1981). Since parentage was unknown, the probability method of Brown and Allard (1970) was used to infer the most likely maternal genotype of each family. The standard error of the ovule frequency of allele, $p$, was estimated as the square root of $p(1-p) / 2 N$, where $N$ is the number of families in the population. The pollen gene frequencies for each family and standard error was obtained via the Expectation-Maximization method (Ritland and Jain, 1981).

Two estimates of outcrossing, $t$ and $t_{\mathrm{H}}$, were obtained for each of the nine populations (table 4 ). These are the two basic approaches to mating system estimation for plants which utilize allozyme data. The first, outcrossing rate $t_{\mathrm{H}}$, is the simplest and makes use of the heterozygosity present in a population at inbreeding equilibrium, whereas outcrossing rate $t$ makes use of progeny genotype arrays or frequencies of genotypes derived from maternal genotypes. The latter generally provides more accurate and reliable information about outcrossing (Ritland 1983). Outcrossing rates $t_{\mathrm{H}}$ were calculated from Wright's inbreeding coefficient, $F$, (Wright, 1969) which was based on observed levels of heterozygosity present at these polymorphic loci. $F$ measures the observed values of inbreeding or the average deviations of progeny genotypic proportions from Hardy-Weinberg expectations and equals zero under panmixia. The genotype data were pooled over all progeny per population and $F$ was calculated as $1-\left(H_{o} / H_{\mathrm{e}}\right)$, where $H_{\mathrm{o}}$ is the observed and $H_{\mathrm{e}}$ is the expected number of heterozygotes, that is, $2 p(1-p)$, where $p$ is the frequency of one allele. The variance of $F$ was calculated by the methods of Phillips and Brown (1977). The outcrossing rate $t_{\mathrm{H}}$ was calculated as $(1-F) /(1+F)$ and the variance of $t_{\mathrm{H}}$ was calculated as $\left[4 /(1+F)^{4}\right] \times$ variance of $F$ (as described in Ritland, 1983). Outcrossing rates $t$ and standard errors were calculated for each locus singly and as a multilocus estimate using the joint maximum likelihood estimation procedures of Ritland and Jain (1981) and Ritland (1986). The multilocus procedure is based on a maximum of three alleles per locus, since determining the maternal genotypes becomes more difficult with greater than three alleles. It was necessary to pool the allele frequencies at locus Pgi-2 for two of the hybrid swarms, since a fourth allele, $0 \cdot 46$, was present at a very low frequency, 0.03 and 0.02 in populations $\mathrm{H} 2$ and $\mathrm{H} 3$, respectively. The frequency of this allele was pooled with the least frequent of the other alleles at this locus (Ritland, 1983). The number of loci included in the multilocus estimate varied from two to three loci for the different populations. A locus was excluded if the frequencies of one of the alleles was greater than 0.98 or if a chi-square test of heterogeneity performed on 


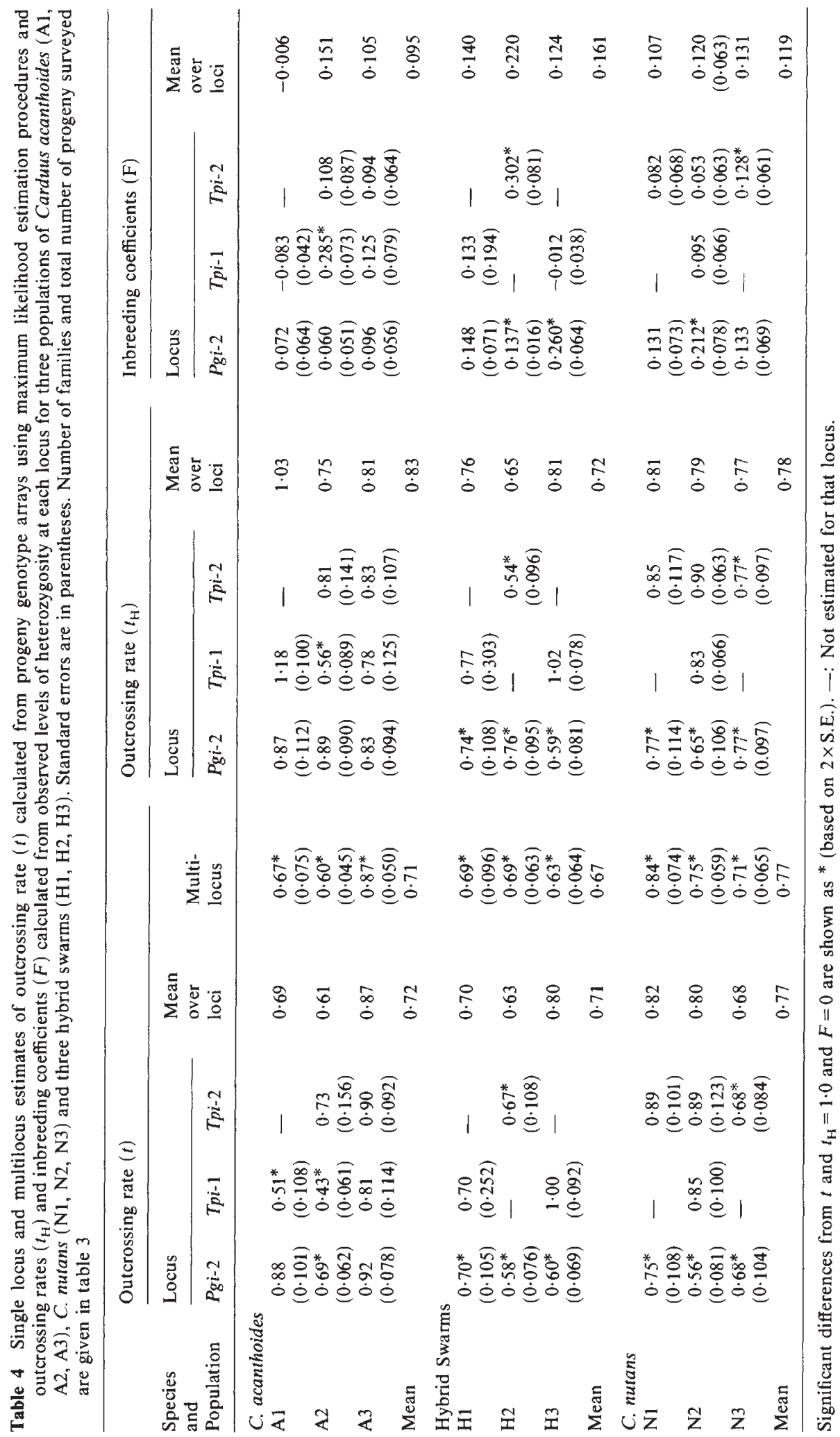


Table 5 Progeny arrays of homozygous maternal plants (genotype inferred), are tested for deviation from a Poisson distribution in order to detect nonrandomness

\begin{tabular}{|c|c|c|c|c|c|c|c|c|c|c|c|c|c|}
\hline \multirow{2}{*}{\multicolumn{2}{|c|}{ Species and population }} & \multirow{2}{*}{$\begin{array}{l}\text { Homozygous } \\
\text { maternal } \\
\text { genotype }\end{array}$} & \multicolumn{10}{|c|}{ No. heterozygous progeny } & \multirow{2}{*}{$\frac{\text { Poisson distribution }}{\chi^{2}(\mathrm{df})}$} \\
\hline & & & 0 & 1 & 2 & 3 & 4 & 5 & 6 & 7 & 8 & 910 & \\
\hline \multirow[t]{7}{*}{ C. acanthoides } & \multirow[t]{2}{*}{ A1 } & $\operatorname{Pg} i-2^{0.43}$ & 10 & 7 & 7 & 2 & 0 & 0 & 0 & 1 & 0 & $0 \quad 0$ & $1.68(3)$ \\
\hline & & $T p i-1^{0 \cdot 70}$ & 20 & 4 & 2 & 0 & 0 & 0 & 1 & 0 & 0 & 00 & $2 \cdot 34(1)$ \\
\hline & \multirow[t]{2}{*}{$\mathrm{A} 2$} & $P g i-2^{0.43}$ & 0 & 3 & 2 & 2 & 1 & 2 & 3 & 0 & 0 & 00 & $4 \cdot 05(5)$ \\
\hline & & $T p i-1^{0 \cdot 70}$ & 6 & 6 & 8 & 5 & 2 & 1 & 0 & 0 & 0 & 00 & $1 \cdot 12(3)$ \\
\hline & \multirow[t]{3}{*}{ A3 } & $\operatorname{Pgi}-2^{0.43}$ & 0 & 1 & 4 & 7 & 3 & 2 & 2 & 1 & 2 & 00 & $3 \cdot 48(6)$ \\
\hline & & $T p i-1^{0.70}$ & 10 & 10 & 4 & 1 & 0 & 0 & 0 & 0 & 0 & 00 & $0 \cdot 16(2)$ \\
\hline & & $T p i-2^{0.49}$ & 7 & 4 & 6 & 4 & 0 & 0 & 0 & 0 & 0 & 00 & $2 \cdot 39(3)$ \\
\hline \multirow[t]{4}{*}{ Hybrid swarms } & $\mathrm{HI}$ & $\operatorname{Pgi}-2^{0-43}$ & 13 & 10 & 3 & 0 & 0 & 1 & 0 & 0 & 0 & $0 \quad 0$ & $0 \cdot 22(2)$ \\
\hline & \multirow[t]{2}{*}{$\mathrm{H} 2$} & $\operatorname{Pgi}-2^{0.43}$ & 10 & 8 & 3 & 4 & 2 & 0 & 0 & 0 & 0 & 00 & $4 \cdot 14(3)$ \\
\hline & & $T p i-2^{0.49}$ & 23 & 2 & 0 & 1 & 0 & 0 & 0 & 1 & 0 & 10 & $14 \cdot 25(2)^{* * *}$ \\
\hline & $\mathrm{H} 3$ & $P g i-2^{0.43}$ & 8 & 4 & 7 & 2 & 0 & 0 & 1 & 0 & 0 & $0 \quad 0$ & $3 \cdot 42(3)$ \\
\hline \multirow[t]{7}{*}{ C. nutans } & \multirow[t]{2}{*}{ N1 } & $\operatorname{Pgi}-2^{0 \cdot 43}$ & 13 & 4 & 2 & 2 & 0 & 0 & 0 & 0 & 0 & $0 \quad 0$ & $2 \cdot 18(2)$ \\
\hline & & Tpi-2 $2^{0.49}$ & 14 & 6 & 1 & 2 & 0 & 0 & 0 & 1 & 0 & 00 & $2 \cdot 76(2)$ \\
\hline & \multirow[t]{3}{*}{ N2 } & $\operatorname{Pgi}-2^{0.43}$ & 6 & 10 & 2 & 8 & 4 & 0 & 0 & 0 & 0 & 00 & $7 \cdot 14(4)$ \\
\hline & & Tpi-1 $1^{0.70}$ & 11 & 8 & 2 & 1 & 0 & 0 & 0 & 0 & 0 & 00 & $0.05(2)$ \\
\hline & & $T p i-2^{0.49}$ & 15 & 9 & 0 & 0 & 0 & 0 & 0 & 0 & 0 & $0 \quad 0$ & $0.43(1)$ \\
\hline & \multirow[t]{2}{*}{ N3 } & $P g i-2^{0.43}$ & 15 & 9 & 2 & 0 & 0 & 0 & 0 & 0 & 0 & 00 & $0 \cdot 10(1)$ \\
\hline & & $T p i-2^{0.49}$ & 7 & 7 & 7 & 2 & 4 & 0 & 1 & 0 & 0 & 00 & $1 \cdot 24(3)$ \\
\hline
\end{tabular}

*** Significant at $P<0 \cdot 001$

the progeny arrays was significant $(P<0 \cdot 01)$, as for $T p i-2$ in population A1.

In multilocus estimation procedures, outcrossing is assumed to be randomly distributed among maternal genotypes within populations. Comparing the distributions of progeny of homozygous maternal genotypes, thus provides a means for testing for spatial heterogeneity in pollen frequencies as might arise if the populations were substructured. If outcrossing is randomly distributed, then the progeny arrays of homozygous maternal plants, i.e. the number of heterozygous progeny, would be expected to have a Poisson distribution. A total of 18 such progeny distributions were tested for goodness of fit to a Poisson distribution using a chi-square test (Sokal and Rohlf, 1969) (table 5).

\section{RESULTS AND DISCUSSION}

\section{Self-fertilization}

Our studies indicated a range of selfing potential among plants of both Carduus species. The mean seed set \pm standard error (S.E.) was $32 \pm 5$ and $68 \pm$ 8 seeds per selfed head for $C$. acanthoides and $C$. nutans, respectively. Seed set values ranged from 10 to 60 and from 20 to 150 seeds per head for $C$. acanthoides and C. nutans, respectively. Based on average estimates of 120 and 250 flowers per head for plants of C. acanthoides and C. nutans, respec- tively (Warwick et al., 1989), the above seed set values correspond to ranges of 8 to 50 per cent and 8 to 60 per cent self-fertility among individuals of $C$. acanthoides and C. nutans, respectively. Our results are similar to that described by Moore and Mulligan (1964) for plants of C. nutans from Grey County, where self-fertility ranged from 0 to 42 per cent, but differed from those of Smyth and Hamrick (1984), who found low seed set in isolated greenhouse plants of $C$. nutans from Kansas. With respect to $C$. acanthoides, our values were higher than those found by Moore and Mulligan (1964), who reported $0-10$ per cent self-fertility among plants originating from Grey County.

\section{Outcrossing rates}

No differences in the frequency of the most common allele at each of three allozyme loci was evident for the progeny, ovule and pollen gene pools based on comparisons of $2 \times$ S.E. of differences between means (table 3 ), providing no evidence of selection during the mating cycle.

Single locus and multilocus estimates of outcrossing rates $t$ and $t_{\mathrm{H}}$ and inbreeding coefficient values $(F)$ are given in table 4 for each of the nine populations. Multilocus estimates of the outcrossing rate, $t$, were significantly less than 1.0 for all nine populations studied (based on $2 \times$ S.E.), with values of $0.84,0.75$, and 0.71 for the three popula- 
tions of $C$. nutans, $0.67,0.60$ and 0.87 for the three populations of $C$. acanthoides and $0.69,0.69$, and 0.63 for the three hybrid swarms. Outcrossing rates $\left(t_{\mathrm{H}}\right)$ estimated from inbreeding coefficient values, $F$, were also clearly less than $1 \cdot 0$. Single locus estimates of $t$ and $t_{\mathrm{H}}$ were more variable, with locus Pgi-2 providing the most consistent result with the multilocus estimates of $t$, especially for the three hybrid swarms and the three populations of $C$. nutans. Similarly single locus estimates of $F$ were highly variable, with values ranging from -0.083 to 0.302 for the nine populations. Estimates were most consistent in the three hybrid swarms with four of the six single locus values showing significant deviations from zero, expected with nonrandom outcrossing. The mating systems of $C$. nutans and $C$. acanthoides in this region are, therefore, both characterized by departures from random outcrossing. Our results for $C$. nutans contrast with the evidence for random outcrossing in two Kansas populations obtained by Smyth and Hamrick (1984) using a similar two-loci, maximumlikelihood estimation procedure. Given the variability among populations in each species, no consistent difference in outcrossing rate was detected for the two parental species. Mean estimates of $t$ and $t_{\mathrm{H}}$ averaged for the three hybrid swarms were consistently less than similar values for the populations of the parental species, although these differences were not statistically significant, and therefore did not provide evidence for differences between pure and hybrid populations of the parental taxa.

There are other factors in addition to selffertilization that can contribute to a departure from random mating in plant populations. Spatial substructuring of populations, assortative mating or variation in outcrossing among maternal genotypes can all shift estimates of $t$ downward (Clegg, 1980; Ritland, 1983). Inbreeding caused by population substructuring can be partly detected by a comparison of single-locus estimates with multilocus estimates, with inbreeding causing a greater downward bias in single-locus estimates (Ritland, 1986). The differences between the mean of the single locus estimates and the multilocus estimate (table 4) are small $(0 \cdot 00$ to $0 \cdot 06)$, with the exception of population $\mathrm{H} 3(0 \cdot 17)$. The lack of a consistent deviation provides little or no evidence that population substructuring is responsible for the lower values of $t$. One of the assumptions in a mixedmating model is that the distribution of progeny over families for a given maternal genotype should be identical. Comparing the distributions of progeny of homozygous maternal genotypes, thus pro- vides a means for testing for spatial heterogeneity in pollen frequencies as might arise if the populations were substructured. Deviations from a Poisson distribution is expected with nonrandom outcrossing. Of a total of 18 such progeny distributions tested; only one family deviated significantly from a Poisson distribution (table 5). These results, therefore, do not provide evidence for spatial heterogeneity in pollen frequencies or substructuring in the populations studied. Recent studies by Smyth and Hamrick (1987) on realized gene flow via pollen and seed in four adjacent, artificial populations of $C$. nutans suggested that population differentiation due to random effects was unlikely in most populations of $C$. nutans. Estimates of effective neighbourhood sizes based on the movement of isozyme makers via pollen was around 252 plants at typical densities of one flowering individual per $\mathrm{m}^{2}$ and was even greater if seed movement was included, ranging from 1281 to 3844 individuals at densities as above.

Heterogeneous outcrossing rates among maternal genotypes would also affect estimates of outcrossing. Variation in outcrossing estimates among individual maternal plants within each of the nine populations was considerable (fig. 2). For most populations, the values were not normally distributed but appeared to be trimodal, suggesting appreciable heterogeneity in outcrossing rates within populations. Smyth and Hamrick (1984) also found significant heterogeneity in apparent outcrossing rates among individuals within two Kansas populations of $C$. nutans.

Genotypic differences in the amount of outcrossing may well be related to genetic differences in self-fertility as observed in greenhouse grown plants or may reflect nonrandom pollinator patterns (Smyth and Hamrick 1984, 1987). Plant population densities may interact with pollinator behaviour to produce considerable inter-plant variation in gene flow. Studies by Smyth and Hamrick (1987) suggested a trend towards greater gene flow with increased density of flower heads of $C$. nutans. There was some correlation between stand density and degree of outcrossing in our Carduus populations. Among populations of C. acanthoides, A3 was the most dense population, forming an almost impenetrable solid stand on the highly disturbed site of an abandoned gravel pit, and had the highest rate of outcrossing. In comparison, plants in the two pasture populations of C. acanthoides, $\mathrm{A} 1$ and $\mathrm{A} 2$, were more widely spaced and had correspondingly lower outcrossing rates. Among populations of $C$. nutans, population $\mathrm{N} 3$ had the lowest outcrossing rate and the lowest 

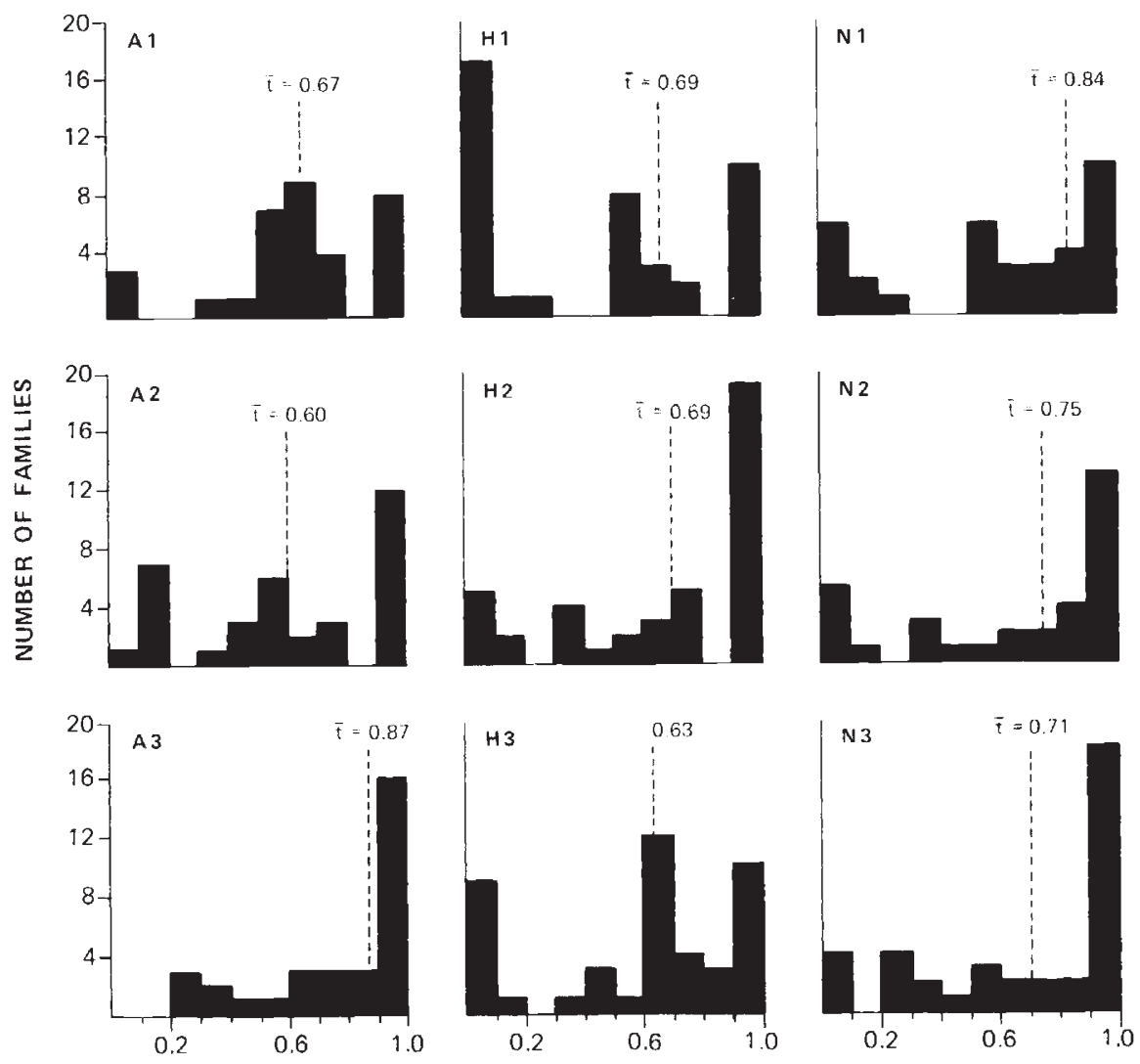

OUTCROSSING RATE ( $t)$

Figure 2 Histograms illustrating variation among maternal genotypes in outcrossing rate $(t)$ for each of three populations of $C$. acanthoides (A1, A2, A3), C. nutans (N1, N2, N3) and the three hybrid swarms (H1, H2, H3). Mean outcrossing rate is given for each population and the sample size for each population is given in table 3 .

population density. Estimates of outcrossing in the hybrid swarms were very similar to each other even though density levels varied among populations.

In conclusion, the mating system of pure populations of $C$. nutans and $C$. acanthoides and their hybrid swarms from Grey County, Ontario exhibited significant departures from random outcrossing, i.e., outcrossing rates were significantly lower than $1 \cdot 0$, presumably due to higher rates of selfing. No consistent differences in outcrossing rates were detected either between the two parental taxa or between the hybrid and pure parental populations. Heterogeneity in outcrossing rates was evident both among populations as well as among maternal plants within populations and may well reflect genetic differences in self-fertility. Such non-obligatory outcrossing should be adaptive in a colonizing species. The ability to self-pollinate when isolated enhances successful colonization following long distance dispersal or at the margin of a distribution range when pollinator frequencies may be reduced, or when seed production may be disrupted as, for example, in hybrid swarms.

Acknowledgements We wish to thank K. Ritland, University of Toronto, for providing access to his computer program for estimating outcrossing rates; and L. Black and G. Cooper for their technical assistance; Drs P. Catling, A. Stahevitch, and P. Jui, Agriculture Canada, Ottawa and two anonymous reviewers for their helpful reviews of the manuscript.

\section{REFERENCES}

BROWN, A. H. D. AND ALLARD, R. W. 1970. Estimation of the mating system in open-pollinated maize populations using isozyme polymorphisms. Genetics, 66, 133-145.

BROWN, A. H. D. AND BURDON, J. J. 1988. Mating systems and colonising success in plants. In Gray, A. J., Crawley M. J. and Edwards, P. J. (eds) Brit. Ecol Soc. Symposium, 26, $115-132$. 
CLEGG, M. T. 1980. Measuring plant mating systems. Bioscience, 230, 814-818.

DESROCHERS, A. M., BAIN, J. F. AND WARWICK, S. I. $1988 a$ 89. The biology of Canadian weeds. Carduus nutans L. and C. acanthoides L. Can. J. Pl. Sci., 68, 1053-1068.

DESROCHERS, A. M., BAIN, J. F. AND WARWICK, S. I. $1988 b$. A biosystematic study of the Carduus nutans L. complex in Canada. Can. J. Bot., 66, 1621-1631.

HAMRICK, J. L. 1982. Plant population genetics and evolution. Amer. J. Bot., 69, 1685-1693.

MOORE, R. J. AND MUlligAN, G. A. 1956. Hybridization between Carduus acanthoides and Carduus nutans in Ontario. Can. J. Bot., 34, 71-85.

MOORE, R. J. AND MULligAN, G. A. 1964. Further studies on natural selection among hybrids of Carduus acanthoides and Carduus nutans. Can. J. Bot., 42, 1605-1613.

PHILlIPS, M. A. AND BROWN, A. H. D. 1977. Mating system and hybridity in Eucalyptus pauciflora. Aust. J. Biol. Sci., 39, 337-344.

RICHARDS, A. J. 1986. Plant Breeding Systems. Allen and Unwin. London.

RITLAND, K. 1983. Estimation of mating systems. In Tanksley, S. D. and Orton, T. J. (eds) Isozymes in Plant Genetics and Breeding, Part A, Elsevier Science Publishers, New York, pp. 289-302.
RITLAND, K. 1986. Joint maximum likelihood estimation of genetic and mating structure. Biometrics, 42, 25-44.

RITLAND, K. AND JAIN, S. K. 1981. A model for the estimation of outcrossing rate and gene frequencies using $n$ independent loci. Heredity, 47, 35-52.

SCHEMSKE, D. W. AND LANDE, R. 1985. The evolution of self-fertilization and inbreeding depression in plants. II. Empirical observations. Evolution, 39, 42-52.

SMYTH, C. A. AND HAMRICK, J. L. 1984. Variation in estimates of outcrossing in musk thistle populations. J. Hered., 75, 303-307.

SMYTH, C. A. AND HAMRICK, J. L. 1987. Realized gene flow via pollen in artificial populations of musk thistle. Evolution, 41, 613-619.

SOKAL, R. R. AND ROHLF, F. J. 1969. Biometry. W. H. Freeman. San Francisco.

WARWICK, S. I. AND BAIN, J. F. 1987. Hybridization and introgression in Carduus nutans and C. acanthoides. Amer. J. Bot., 74, 764 [Abst.].

WARWICK, S. I., BAIN, J. F., WHEATCROFT, R. AND THOMPSON, B. K. 1989. Hybridization and introgression in Carduus nutans and C. acanthoides. Syst. Bot., 14, 476-494.

WRIGHT, S. 1969. Evolution and Genetics of Populations, Volume II. The Theory of Gene Frequencies. University of Chicago Press, Chicago. 